\title{
Inhibition of Aspergillus flavus in Soil by Antagonistic Pseudomonas Strains Reduces the Potential for Airborne Spore Dispersal
}

\author{
Jeffrey D. Palumbo, Teresa L. O’Keeffe, Ali Kattan, Hamed K. Abbas, and Bobbie J. Johnson
}

First, second, and third authors: U.S. Department of Agriculture-Agricultural Research Service (USDA-ARS), Plant Mycotoxin Research Unit, Albany CA 94710; and fourth and fifth authors: USDA-ARS, Crop Genetics and Production Research Unit, Stoneville, MS 38776. Accepted for publication 26 January 2010.

\section{ABSTRACT}

Palumbo, J. D., O’Keeffe, T. L., Kattan, A., Abbas, H. K., and Johnson, B. J. 2010. Inhibition of Aspergillus flavus in soil by antagonistic Pseudomonas strains reduces the potential for airborne spore dispersal. Phytopathology 100:532-538.

Pseudomonas chlororaphis strain JP1015 and P. fluorescens strain JP2175 were previously isolated from Mississippi cornfield soil samples and selected for their growth inhibition of Aspergillus flavus in laboratory culture. In this study, the antifungal activity of these bacterial strains against $A$. flavus in soil coculture was determined. Growth of A. flavus was inhibited up to 100 -fold by P. chlororaphis strain JP1015 and up to 58-fold by $P$. fluorescens strain JP2175 within 3 days following soil coinoculation. A. flavus propagule densities after 16 days remained 7- to 20 -fold lower in soil treated with either bacterial strain. Using a benchscale wind chamber, we demonstrated that treatments of soil with $P$. chlororaphis strain JP1015 and P. fluorescens strain JP2175 reduced airborne spores dispersed across a $1 \mathrm{~m}$ distance by 75 - to 1,000-fold and 10- to 50-fold, respectively, depending on soil type and inoculum level. These results suggest that application of these bacterial strains may be effective in reducing soil populations of mycotoxigenic fungi, thereby reducing fungal spore formation, and ultimately reducing the potential for crop plant infection via airborne transmission.

Additional keywords: maize (Zea mays), rhizosphere.
Aspergillus flavus is a ubiquitous resident of agricultural soils and is associated with many crops. In corn (maize, Zea mays L.), this fungus is one of several fungal pathogens that cause ear rot. More critically, A. flavus produces aflatoxins, which reduce the quality and safety of the crop (4,32). Aflatoxins are highly potent carcinogens and mutagens; as such, aflatoxin contamination of corn is an issue of both human and animal health (12). In addition, several countries worldwide have regulatory limits on aflatoxin levels in corn and other commodities, resulting in an increased economic burden to growers, processors, and livestock producers (36).

One method to reduce aflatoxin contamination of corn is to reduce the frequency or extent of A. flavus infection. This has been investigated using modifications of cultural practices (10, 27 ), as well as conventional and molecular breeding to introduce traits conferring resistance to fungal infection $(1,8,26)$ or resistance to insect damage that directly impacts fungal infection $(6,24)$. Chemical methods that have been studied include the use of insecticides to reduce insect damage and thereby reduce susceptibility to mycotoxin contamination (17). In contrast, experimental evidence showed that sublethal application of the fungicides miconazole, tridemorph, fenpropimorph, and fenarimol actually increased production of aflatoxins by $A$. parasiticus $(5,11)$. This may be indicative of a mechanism akin to oxidative stress response, which is involved in regulation of aflatoxin biosynthesis $(22,23)$. Studies of biological methods for reducing aflatoxigenic A. flavus infection in corn have largely focused on the use of nonaflatoxigenic strains of A. flavus $(2,9,16)$, which act by competitively displacing toxigenic strains. Other studies have

Corresponding author: J. D. Palumbo; E-mail address: jeffrey.palumbo@ars.usda.gov

doi:10.1094/PHYTO-100-6-0532

This article is in the public domain and not copyrightable. It may be freely reprinted with customary crediting of the source. The American Phytopathological Society, 2010. examined inhibition of A. flavus using bacterial isolates, predominantly Bacillus spp. (7,28) and Pseudomonas spp. (3), as well as Acremonium zeae, a corn endophyte (37).

In previous work (31), we isolated several strains of Pseudomonas, Bacillus, and Burkholderia, among other species, from corn soil and rhizosphere samples and screened them for antifungal activity against $A$. flavus using in vitro assays in different culture media. Two isolates, a $P$. chlororaphis strain and a $P$. fluorescens strain, showed consistent fungal growth inhibition in liquid media. To further investigate their antagonism against $A$. flavus, we developed soil coculture assays in which fungal and bacterial populations were quantified over time. Since soil is an important inoculum source of A. flavus (15), we hypothesized that reducing vegetative populations in soil may reduce the inoculum potential of that soil. In addition, we hypothesized that reduction of A. flavus growth in soil would result in reduced potential for the airborne dispersal of A. flavus spores. This would, in turn, reduce the potential for $A$. flavus infection and subsequent aflatoxin contamination of nearby crop plants. To test this hypothesis, we developed a laboratory-scale wind chamber assay to quantify windborne A. flavus spores following conidial development in soil following coculture with bacterial isolates.

\section{MATERIALS AND METHODS}

Strains and media. $P$. chlororaphis strain JP1015 and $P$. fluorescens strain JP2175 were previously isolated from cornfield soil and corn rhizosphere samples, respectively (31). Bacterial strains were maintained on $0.1 \times$ Difco tryptic soy agar (TSA) (Becton, Dickinson \& Co., Franklin Lakes, NJ) and grown at $28^{\circ} \mathrm{C}$ with shaking in $0.5 \times$ Bacto tryptic soy broth (Becton, Dickinson \& Co.). A. flavus strain F3W4 (2) cultures were maintained on potato dextrose agar (PDA) (Becton, Dickinson \& Co.) at $28^{\circ} \mathrm{C}$ in darkness. Fungal spores were prepared in $30 \%$ glycerol with $0.05 \%$ Tween 80 from freshly sporulating cultures. Spore density was determined using a hemacytometer and suspen- 
sions were stored in $1-\mathrm{ml}$ aliquots at $-70^{\circ} \mathrm{C}$. Conidial viability of the suspensions was periodically verified by enumeration on $A$. flavus and A. parasiticus agar (AFPA) (33).

Soil preparation. Two soil types were collected from USDA experimental agricultural plots in Mississippi that had been planted in corn: "Field 2" soil (F2) was characterized as a Dundee silty clay soil (fine-silty, mixed thermic Aeric Ochraqualfs), $\mathrm{pH}$ 6.5, and "Field 6" soil (F6) was characterized as a Beulah fine sandy loam soil (coarse-loamy, mixed thermic Typic Dystrochrepts), $\mathrm{pH}$ 6.4. Both soils were air dried in plastic tubs for 4 days, sifted through a $2.36-\mathrm{mm}$ pore size sieve (no. 8 USA standard testing sieve, Gilson Co., Inc., Lewis Center, $\mathrm{OH}$ ) and stored in airtight polyethylene bags at $4^{\circ} \mathrm{C}$. In preparation for fungal growth experiments, $15 \mathrm{ml}$ of distilled water was added to $150 \mathrm{~g}$ of soil in a magenta box, allowed to stand for $30 \mathrm{~min}$, and autoclaved for $60 \mathrm{~min}$ with $15 \mathrm{~min}$ slow exhaust. After cooling, autoclaved soil was mixed by shaking each box vigorously in all directions for $60 \mathrm{~s}$.

Soil antagonism assays. For each experiment, $10 \mathrm{~g}$ of autoclaved soil was weighed into petri dishes $\left(60 \times 15 \mathrm{~mm}^{2}\right)$ and hydrated with $1 \mathrm{ml}$ of sterile distilled water by evenly pipetting over the entire soil surface. Hydrated soil plates were allowed to stand for $30 \mathrm{~min}$ to allow even absorption. Spore suspensions of A. flavus strain F3W4 were diluted to approximately $10^{5}$ conidia/ $\mathrm{ml}$ and $1 \mathrm{ml}$ was pipetted evenly over the surface of each soil plate, for a target inoculation of approximately $10^{4}$ conidia per gram of soil. Viable inoculum concentrations were enumerated by dilution plating on PDA. Overnight $(18 \mathrm{~h})$ bacterial cultures were pelleted by centrifugation for $2 \mathrm{~min}$ at $12,000 \times g$ and resuspended in sterile $0.05 \%$ Tween 80 . Suspensions were serially diluted in sterile $0.05 \%$ Tween 80 to contain approximately $10^{4}$, $10^{6}$, or $10^{8} \mathrm{CFU} / \mathrm{ml}$. These suspensions were serially diluted and plated onto $0.1 \times$ TSA for enumeration. One-milliliter aliquots of each bacterial suspension were pipetted evenly over the surface of each soil treatment, for a target inoculation of approximately $10^{3}$, $10^{5}$, or $10^{7} \mathrm{CFU} / \mathrm{g}$ of soil. Sterile $0.05 \%$ Tween $80(1 \mathrm{ml})$ was added to fungus-only control treatments. Soil plates were parafilmed and incubated at $28^{\circ} \mathrm{C}$ in darkness. To retard dehydration of the soil, a pan of distilled water was placed at the bottom of the incubator throughout the experiment.

Bacterial and fungal populations in each soil treatment were enumerated 3,6,9,12, and 16 days following inoculation. One gram of soil per dish was weighed into $9 \mathrm{ml}$ of sterile $0.05 \%$ Tween 80 , vortexed for $30 \mathrm{~s}$, and serially diluted in sterile $0.05 \%$ Tween 80. For A. flavus enumeration, dilutions were spread plated onto AFPA supplemented with streptomycin at $100 \mathrm{mg} / \mathrm{liter}$. Fungal dilution plates were incubated for 2 days at $28^{\circ} \mathrm{C}$. Bacterial enumeration was performed by plating of appropriate sample dilutions using an Autoplate 4000 spiral plater (Spiral Biotech, Norwood, MA) onto $0.1 \times$ TSA supplemented with cycloheximide at $100 \mathrm{mg} /$ liter. Bacterial dilution plates were incubated for 18 to $20 \mathrm{~h}$ at $28^{\circ} \mathrm{C}$. For each experiment, treatments with each bacterial inoculum density were performed in triplicate. The experiment was repeated, for a total of six replicate samples per treatment.

Windborne spore dispersal assays. A bench-scale wind chamber was constructed using a 20-cm-diameter acrylic tube, $1 \mathrm{~m}$ in length (TAP Plastics, El Cerrito, CA). A 12-cm-diameter fan (Alpha V TA450, Nidec America, Norwood, MA) was fixed to a 20-cm diameter soil sieve (no. 18 USA standard testing sieve, Gilson, Co.), which slid onto one end of the tube. The fan displaced air at a rate of 2,800 liters/min at 3,200 rpm, resulting in an apparent wind speed of $4.5 \mathrm{~km} / \mathrm{h}$ at the downwind end of the chamber. To measure bacterial effects on production of windborne A. flavus spores, experimental treatments consisted of $10 \mathrm{~g}$ of autoclaved soil (F2 or F6) in petri dishes $\left(60 \times 15 \mathrm{~mm}^{2}\right)(=28.3$ $\mathrm{cm}^{2}$ surface area), inoculated with $10^{4}$ A. flavus conidia/g, and 0 , $10^{3}, 10^{5}$, or $10^{7} \mathrm{CFU} / \mathrm{g}$ of each bacterial strain, as described above, except that soil was not hydrated prior to inoculation. Soil plates were parafilmed and incubated at $28^{\circ} \mathrm{C}$ in darkness. Following incubation for 7 or 14 days, the lids were removed, and test samples were placed in the wind chamber, approximately $3 \mathrm{~cm}$ directly in front of the fan. At the downwind end of the chamber, approximately $1 \mathrm{~m}$ from the fan, 100 liter air samples were collected using a MicroBio MB2 air sampler (F.W. Parrett Ltd., London, UK) at a rate of 100 liters/min. This air sampler is designed to collect airborne particles on media in petri dishes and was positioned with its sampling inlets perpendicular to the airflow to allow for collection in dishes containing either agar or liquid diluent. Windborne spore samples were collected directly onto AFPA + streptomycin plates, or into $10 \mathrm{ml}$ of $0.05 \%$ Tween 80 and subsequently dilution plated onto AFPA + streptomycin plates, and incubated for 2 days at $28^{\circ} \mathrm{C}$ to enumerate $A$. flavus colonies. For each experiment, treatments with each bacterial inoculum density were performed in triplicate. To prevent carryover of spores between samples, the chamber was sanitized with $70 \%$ ethanol after each sample collection. Experiments were performed three times for a total of nine replicate samples per treatment.

Statistical analyses. For soil antagonism assays, fungal and bacterial population data were log-transformed prior to statistical analysis. Data from windborne spore dispersal assays were log $(n+1)$ transformed to account for incidences when colony counts were zero. Differences in populations among treatments were analyzed at each time point by one-way analysis of variance with Tukey's post-test using GraphPad Instat (version 3.06, GraphPad Software, Inc., San Diego, CA).

\section{RESULTS}

Fungal growth characteristics in soil. Initial experiments were performed to determine growth characteristics of $A$. flavus in nonsterile cornfield soils. Growth in F2 and F6 soils was almost completely inhibited over 10 days following inoculation at low levels $\left(10^{3}\right.$ conidia/g) or high levels $\left(10^{6}\right.$ conidia/g), indicating antifungal microbial activity in these soils. Recovered fungal propagule levels tended to remain at or near the inoculum levels during this time, suggesting that conidia remained viable. In contrast, autoclaved soils supported vegetative growth of $A$. flavus. Within 3 days following inoculation, extensive sporulation was apparent on the surface of soil samples inoculated with $A$. flavus. The fungal growth inhibition of nonsterile soil and its inactivation by autoclaving was further observed on agar media prepared using aqueous washes of nonsterile soil versus autoclaved soil. Therefore, autoclaved soils were used for subsequent experiments to determine antagonistic effects of Pseudomonas strains.

Inhibition of $A$. flavus growth in soil. Both $P$. chlororaphis strain JP1015 and $P$. fluorescens strain JP2175 significantly reduced the recovered number of A. flavus propagules in soil coculture assays relative to control treatments inoculated with $A$. flavus only (Figs. 1 and 2). Three days after coinoculation in F2 soil, $P$. chlororaphis strain JP1015 reduced A. flavus populations by more than 150 -fold when inoculated at $10^{5}$ or $10^{7} \mathrm{CFU} / \mathrm{g}(P<$ $0.001)$, and by 25 -fold when inoculated at $10^{3} \mathrm{CFU} / \mathrm{g}(P<0.001)$ (Fig. 1A). By day 16, A. flavus populations were 20 -fold reduced in coculture treatments relative to control treatments $(P<0.001)$, regardless of the starting bacterial inoculum. Similar A. flavus growth inhibition by $P$. chlororaphis strain JP1015 occurred in F6 soil (Fig. 1B). At day 3, A. flavus populations were reduced by more than 100 -fold by $10^{5}$ or $10^{7} \mathrm{CFU} / \mathrm{g}$ of $P$. chlororaphis strain JP1015 $(P<0.001)$, and by 15 -fold by $10^{3} \mathrm{CFU} / \mathrm{g}$ of the bacterium $(P<0.001)$. By day 16 in F6 soil, A. flavus populations were 10 to 20 -fold reduced in coculture treatments relative to control treatments $(P<0.001)$. At all time points, $A$. flavus populations did not significantly differ between soil types for equivalent treatments $(P>0.05)$. 
In contrast, the dose dependence of A. flavus inhibition by $P$. fluorescens strain JP2175 was much more pronounced (Fig. 2). At day 3 in F2 soil, $P$. fluorescens strain JP2175 inoculum levels of $10^{5}$ and $10^{7} \mathrm{CFU} / \mathrm{g}$ reduced $A$. flavus populations by 25 -fold $(P<$ $0.001)$ and 74 -fold $(P<0.001)$, respectively, whereas the $10^{3}$ $\mathrm{CFU} / \mathrm{g}$ inoculum level reduced $A$. flavus by 5 -fold, which was not significant $(P>0.05)$ (Fig. 2A). At day 16, A. flavus populations were reduced 7 -fold $(P<0.05)$ and 13 -fold $(P<0.001)$ in treatments inoculated with $10^{5}$ and $10^{7} \mathrm{CFU} / \mathrm{g}$, respectively, but in $10^{3}$ CFU/g treatments, A. flavus populations were reduced only 3-fold, which was not significant $(P>0.05)$. Similar levels of $A$. flavus inhibition by $P$. fluorescens strain JP2175 were observed in F6 soil (Fig. 2B). A. flavus populations were reduced by 14 -fold $(P<$ $0.001)$ and 58 -fold $(P<0.001)$ by coinoculation with $P$. fluorescens strain JP2175 at $10^{5}$ and $10^{7} \mathrm{CFU} / \mathrm{g}$, respectively, but only by 4 -fold (not significant, $P>0.05$ ) by $10^{3} \mathrm{CFU} / \mathrm{g}$ of the bacterium. At day 16, A. flavus populations were reduced 7 -fold $(P<0.05)$ and $10-$ fold $(P<0.01)$ in treatments inoculated with $10^{5}$ and $10^{7} \mathrm{CFU} / \mathrm{g}$, respectively, while A. flavus populations in $10^{3} \mathrm{CFU} / \mathrm{g}$ treatments were reduced only 2 -fold (not significant, $P>0.05$ ). As with $P$. chlororaphis strain JP1015, fungal populations were not significantly different between soil types for equivalent treatments with $P$. fluorescens strain JP2175 at all time points $(P>0.05)$.

Growth and survival of bacteria. Both $P$. chlororaphis strain JP1015 and $P$. fluorescens strain JP2175 grew quickly in F2 and F6 soils, reaching maximum population densities by 3 days after inoculation (Figs. 3 and 4). In F2 soil coinoculated with A. flavus, P. chlororaphis strain JP1015 populations grew to nearly $10^{9} \mathrm{CFU} / \mathrm{g}$ and persisted at densities greater than $10^{8} \mathrm{CFU} / \mathrm{g}$ until day 16 , regardless of the starting inoculum density (Fig. 3A). P. chlororaphis strain JP1015 grew to $10^{9} \mathrm{CFU} / \mathrm{g}$ in F6 soil coinoculated with $A$. flavus, but populations declined significantly $(P<0.001)$ by day 16 , to less than $10^{6} \mathrm{CFU} / \mathrm{g}$ and less than $10^{8} \mathrm{CFU} / \mathrm{g}$ in soils inoculated with $10^{3} \mathrm{CFU} / \mathrm{g}$, and $10^{5}$ or $10^{7} \mathrm{CFU} / \mathrm{g}$, respectively (Fig. 3B). In both soils at all inoculum densities, $P$. fluorescens strain JP2175 populations reached $10^{9} \mathrm{CFU} / \mathrm{g} 3$ days after inoculation, and persisted at densities greater than $10^{8} \mathrm{CFU} / \mathrm{g}$ until day 16 (Fig. 4).

Recovery of windborne spores. Following incubation for 7 days, soil inoculated with $A$. flavus alone showed extensive surface sporulation, whereas surface sporulation was not observed in soil coinoculated with $A$. flavus and $P$. chlororaphis strain JP1015 or $P$. fluorescens strain 2175 . In order to quantify this observation, a bench-scale wind chamber was constructed to model windborne dispersal of A. flavus spores following soil coculture with bacterial antagonists (Fig. 5). Air samples collected $1 \mathrm{~m}$ downwind of $A$. flavus-inoculated soil plates yielded $1.8 \times$ $10^{3}$ and $3.0 \times 10^{3}$ windborne propagules (conidia) per plate from F2 and F6 soils, respectively, after 7 days of incubation, and $2.0 \times$ $10^{3}$ and $3.5 \times 10^{3}$ conidia per plate from F2 and F6 soils, respectively, after 14 days of incubation (Fig. 6). Following coculture of A. flavus with $P$. chlororaphis strain JP1015 in F2 soil, the number of conidia recovered from air samples was significantly reduced $(P<0.001)$, by 75 -fold to 100 -fold after 7 days of incubation, and by 100 -fold to 150 -fold after 14 days of incubation (Fig. 6A). In F6 soil, the initial dose-dependent inhibition of $A$. flavus growth by $P$. chlororaphis strain JP1015 (Fig. 1B) was reflected in dose-dependent reduction in windborne spore recoveries (Fig. 6B). At $10^{5}$ and $10^{7} \mathrm{CFU} / \mathrm{g}$ of P. chlororaphis strain JP1015 soil inocula, spore recoveries were 700 -fold lower than from A. flavus-only soil after 7 days $(P<0.001)$, and 900-fold to 1,000 -fold lower after 14 days $(P<0.001)$. In contrast, spore recoveries following soil inoculation with $10^{3} \mathrm{CFU} / \mathrm{g}$ of $P$. chlororaphis strain JP1015 were reduced by 150 -fold after 7 days $(P<0.001)$, and 300-fold after 14 days $(P<0.001)$, which were significantly greater than recoveries from the higher bacterial inoculation rates $(P<0.001)$. Soil type affected bacterial reduction of windborne spores, with recoveries from F6 soils inoculated with $10^{5}$ or $10^{7} \mathrm{CFU} / \mathrm{g}$ of $P$. chlororaphis strain JP1015 significantly lower than those from F2 soils with equivalent treatments at both 7 days $(P<0.001)$ and 14 days $(P<0.05)$ following inoculation.

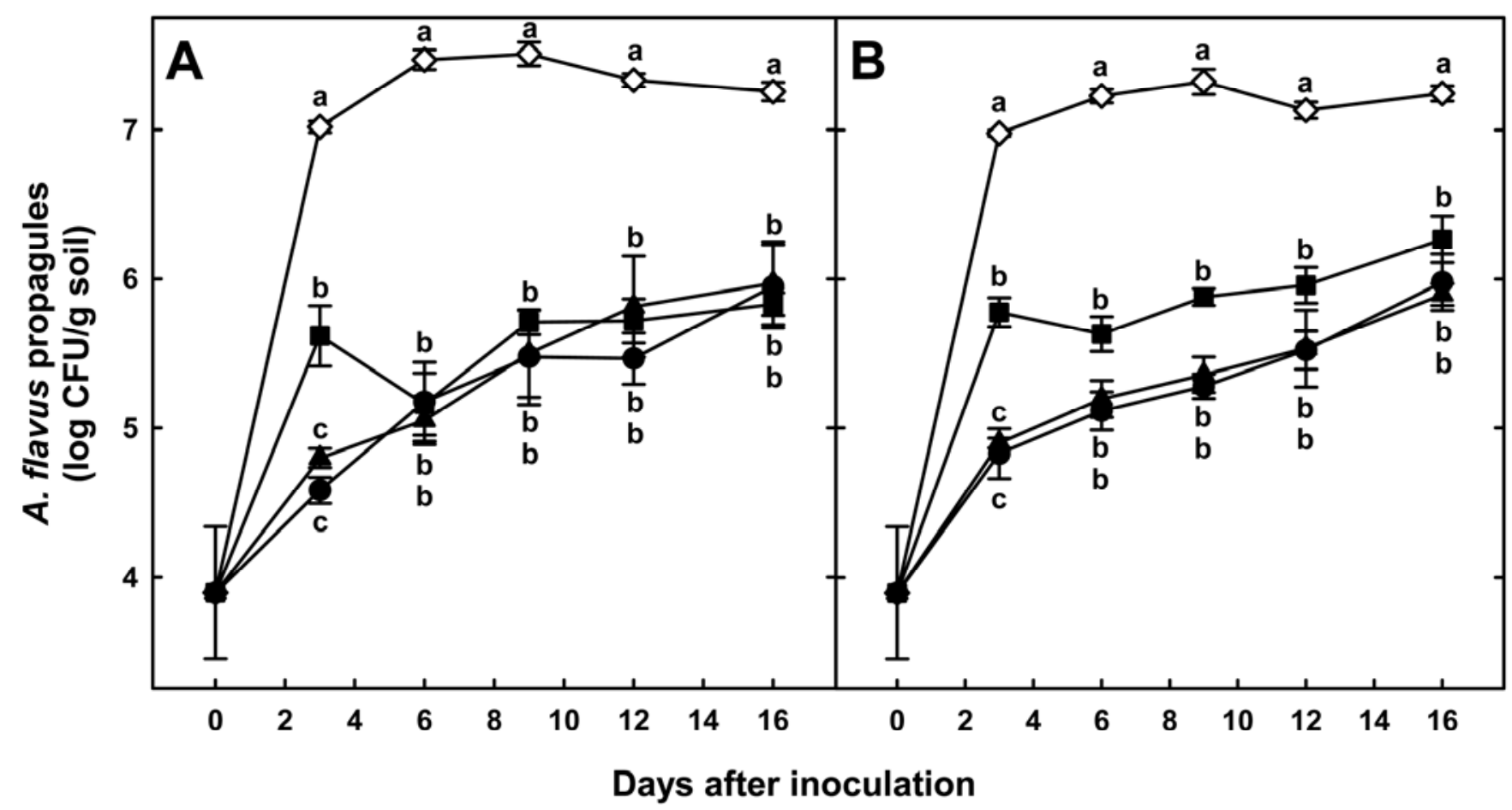

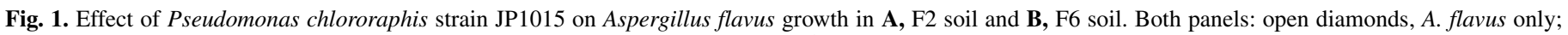

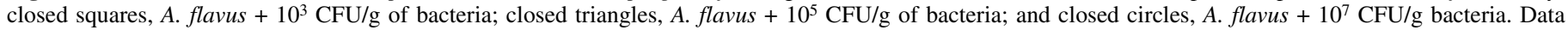

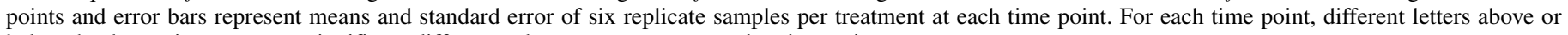
below the data points represent significant differences between treatments at that time point. 
Windborne spores recovered from soils coinoculated with $A$. flavus and $P$. fluorescens strain JP2175 were also significantly lower than from $A$. flavus-only soils $(P<0.001)$, but significantly higher than with $P$. chlororaphis strain JP1015 $(P<0.01)$. In F2 soil, $P$. fluorescens strain JP2175 treatments reduced spore recoveries by 10 -fold to 25 -fold after 7 days, and by 10 -fold to 20 -fold after 14 days, independent of starting bacterial inoculum levels (Fig. 6C). In contrast, treatments in F6 soil (Fig. 6D) showed significant bacterial inoculum dose response after 7 days
$(P<0.001)$, with recoveries reduced by 50 -fold $\left(10^{7} \mathrm{CFU} / \mathrm{g}\right.$ of inoculum), 30-fold (10 $\mathrm{CFU} / \mathrm{g}$ of inoculum), and 10-fold ( $10^{3} \mathrm{CFU} / \mathrm{g}$ of inoculum), in a trend similar to reduction in $A$. flavus populations recovered from soil (Fig. 2). However, this effect was not observed after 14 days, with conidia recoveries reduced by 15 -fold to 20 -fold, regardless of bacterial inoculum level. In contrast to $P$. chlororaphis strain JP1015 treatments, soil type did not significantly affect the reduction of windborne spores by $P$. fluorescens strain JP2175 $(P>0.05)$.

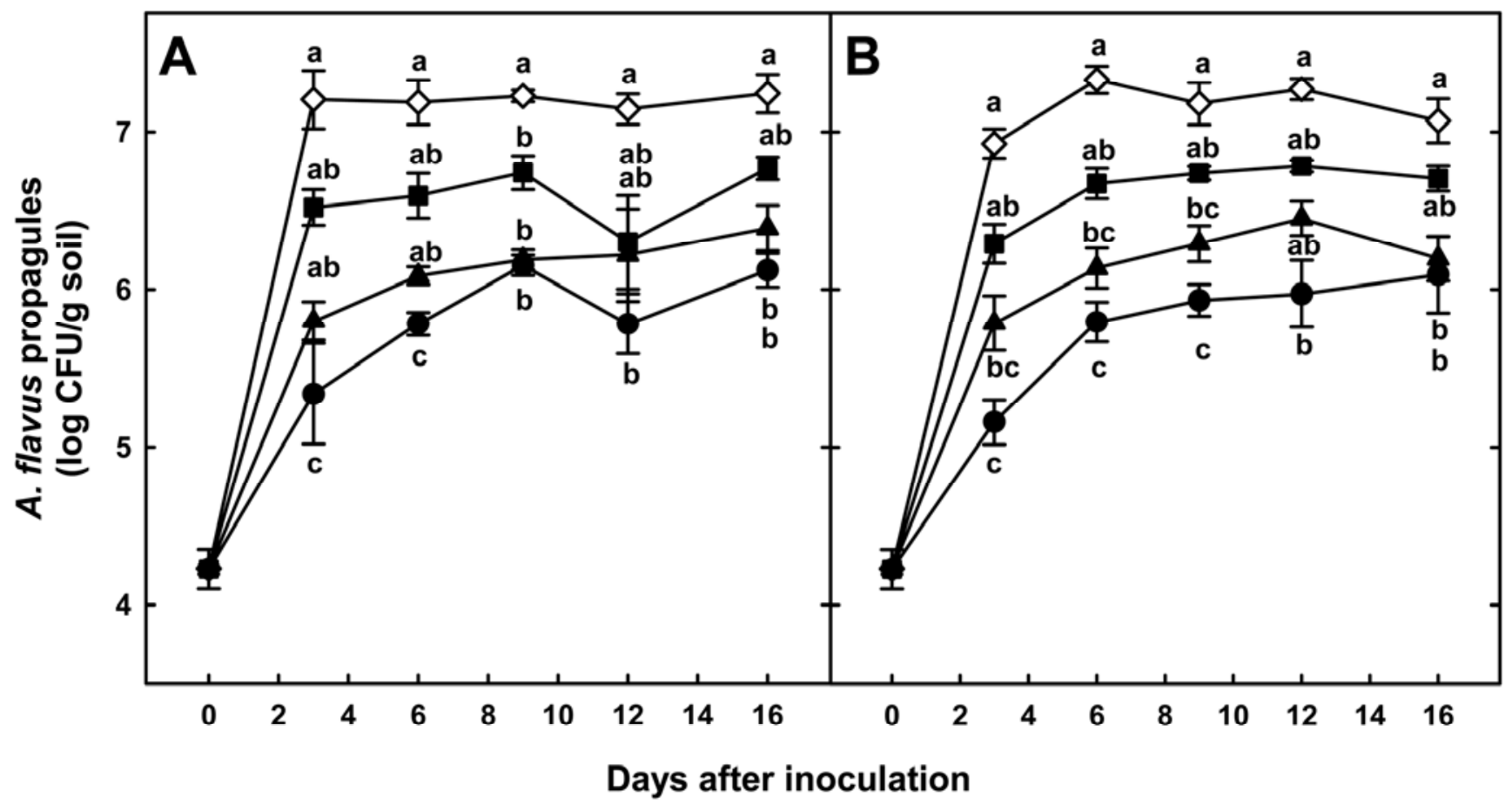

Fig. 2. Effect of Pseudomonas fluorescens strain JP2175 on Aspergillus flavus growth in A, F2 soil and B, F6 soil. Both panels: open diamonds, A. flavus only; closed squares, A. flavus $+10^{3} \mathrm{CFU} / \mathrm{g}$ of bacteria; closed triangles, A. flavus $+10^{5} \mathrm{CFU} / \mathrm{g}$ of bacteria; and closed circles, A. flavus $+10^{7} \mathrm{CFU} / \mathrm{g}$ of bacteria. Data points and error bars represent means and standard error of six replicate samples per treatment at each time point. For each time point, different letters above or below the data points represent significant differences between treatments at that time point.

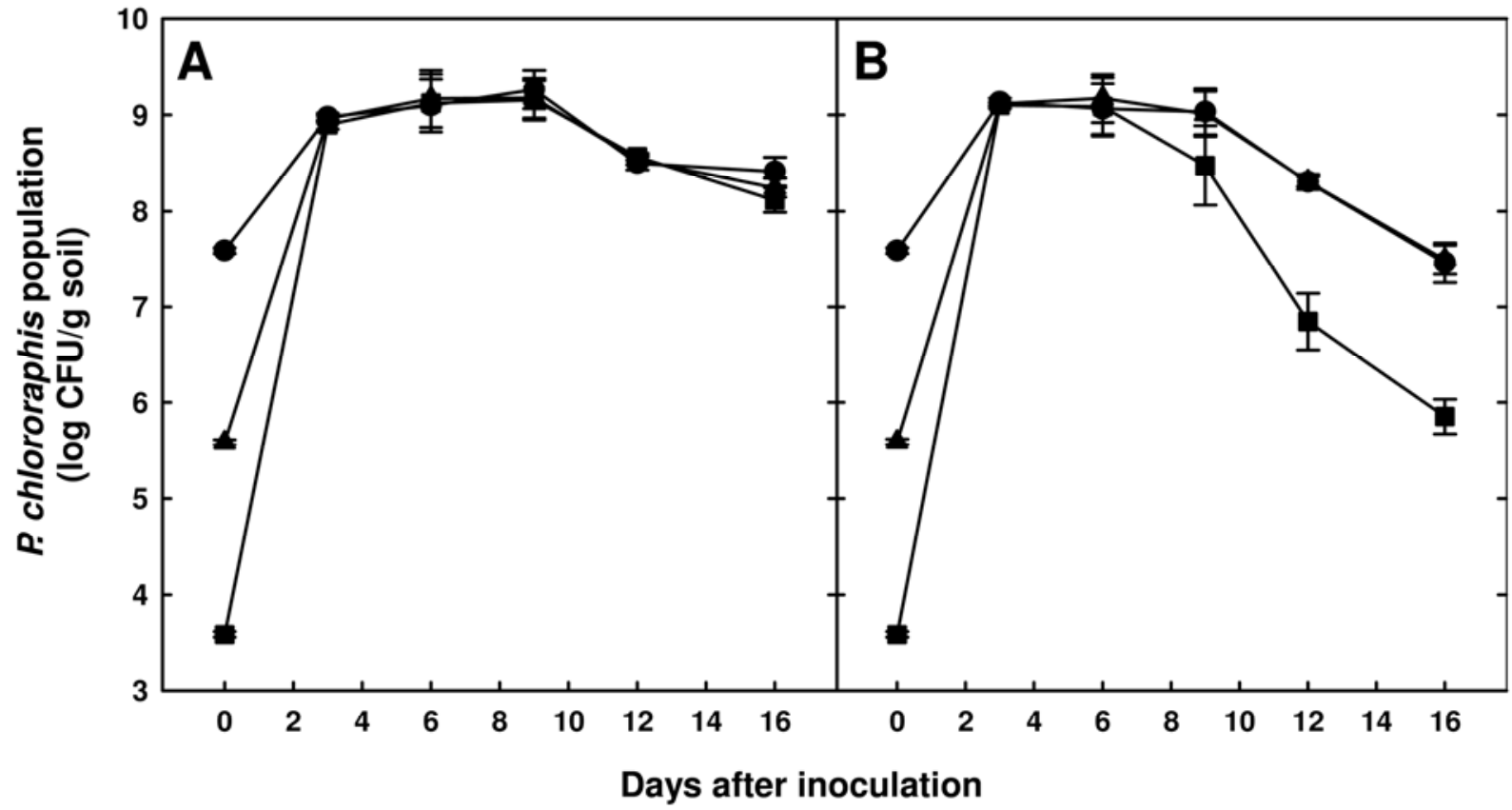

Fig. 3. Pseudomonas chlororaphis strain JP1015 growth in A, F2 soil and B, F6 soil. Both panels: closed squares, Aspergillus flavus $+10^{3}$ CFU/g of bacteria; closed triangles, A. flavus $+10^{5} \mathrm{CFU} / \mathrm{g}$ of bacteria; and closed circles, A. flavus $+10^{7} \mathrm{CFU} / \mathrm{g}$ of bacteria. Data points and error bars represent means and standard error of six replicate samples per treatment at each time point. 


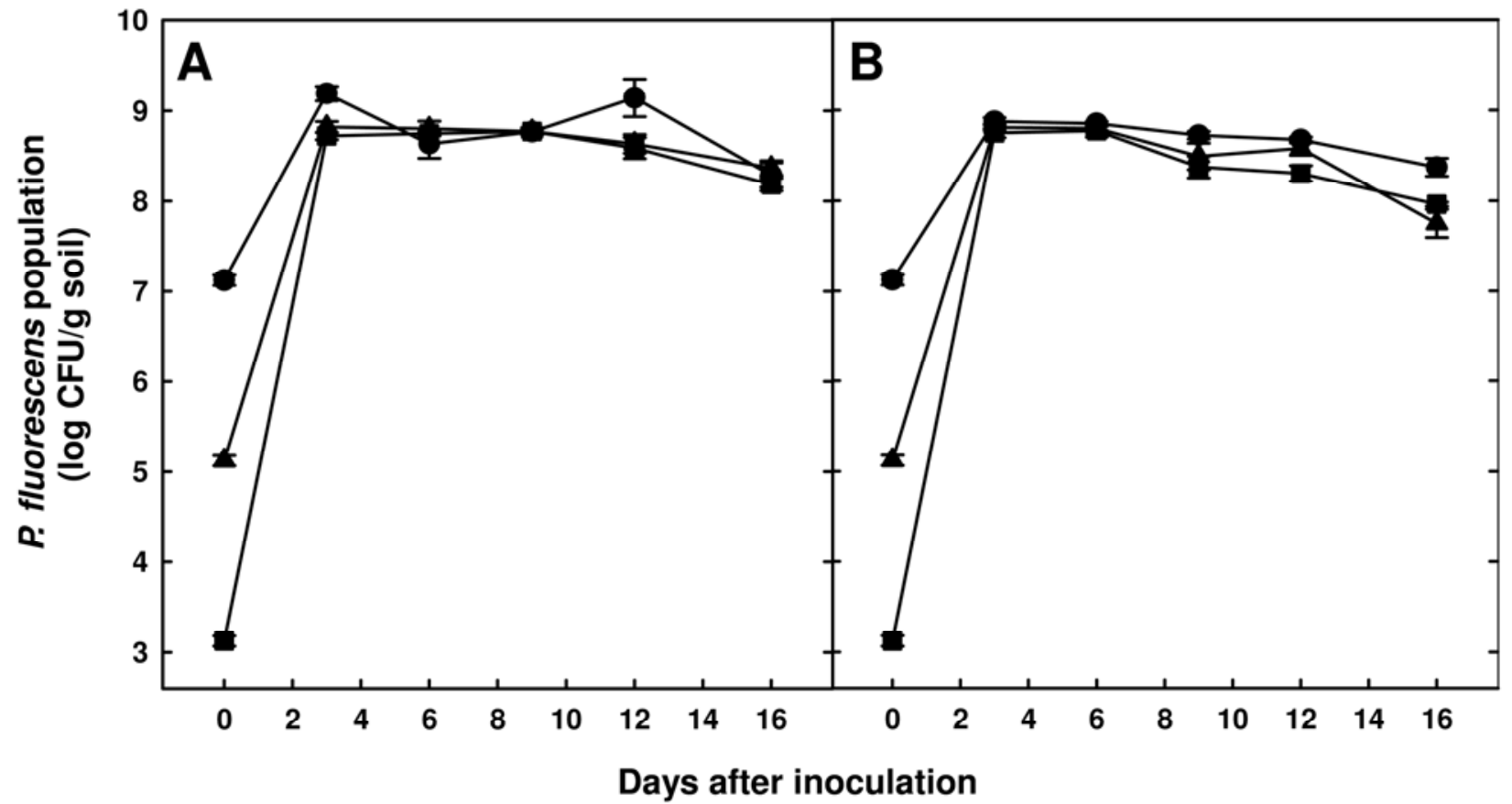

Fig. 4. Pseudomonas fluorescens strain JP2175 growth in A, F2 soil and B, F6 soil. Both panels: closed squares, Aspergillus flavus $+10^{3} \mathrm{CFU} / \mathrm{g}$ bacteria; closed triangles, A. flavus $+10^{5} \mathrm{CFU} / \mathrm{g}$ of bacteria; and closed circles, A. flavus $+10^{7} \mathrm{CFU} / \mathrm{g}$ of bacteria. Data points and error bars represent means and standard error of six replicate samples per treatment at each time point.

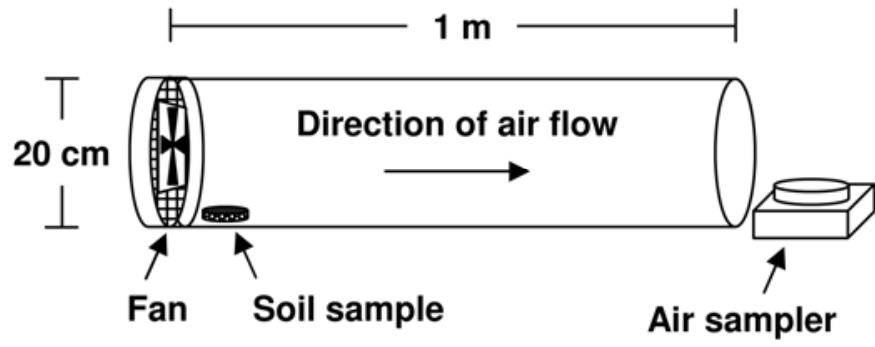

Fig. 5. Schematic diagram of bench-scale wind chamber used in this study. The entire apparatus was operated in a biological safety cabinet to contain the dispersal of windborne Aspergillus flavus spores.

\section{DISCUSSION}

This is the first report to describe the correlation between bacterial inhibition of $A$. flavus growth in soil and the reduction of windborne spore dispersal. In this study, we demonstrated that $P$. chlororaphis strain JP1015 and P. fluorescens strain JP2175 reduce vegetative populations of $A$. flavus recovered from corn field soils (Figs. 1 and 2). This growth inhibition led to greatly reduced sporulation on the surface of coinoculated soil. Using a bench-scale wind chamber (Fig. 5), we demonstrated that this inhibition of sporulation resulted in reduced numbers of $A$. flavus spores collected $1 \mathrm{~m}$ downwind of the treated soil (Fig. 6). Since A. flavus contamination of aerial crops such as maize occurs primarily by windborne spore dispersal (15), this represents an important consideration for the development of biological interventions for controlling aflatoxin contamination.

The strains of $P$. chlororaphis and $P$. fluorescens used in this study were isolated previously from F2 and F6 cornfield soil and corn rhizosphere samples, and selected for antagonistic activity against $A$. flavus and $F$. verticillioides in laboratory culture (31). To further investigate the antagonistic potential of these bacteria, soil coculture assays were developed to measure inhibition of $A$. flavus vegetative growth and spore dispersal. Using the same soils from which these bacterial strains were isolated, both bacteria demonstrated antifungal activity, consistent with effects shown in culture media. In other studies investigating potential bacterial biocontrol agents against mycotoxigenic A. flavus or Fusarium verticillioides, characterization of antifungal activity has been determined typically using laboratory media, followed by greenhouse or field studies $(3,7,13,14,21)$. However, antifungal assays using soils prior to field application may be a beneficial intermediate step in development of biocontrol candidates, in that unnecessary time and expense would be saved by eliminating poorly performing candidates before designing field studies.

Both soils tested in this study, a Dundee silty clay and a Beulah fine sandy loam, did not support growth of A. flavus in their nonsterile state. In addition, fungal growth was inhibited in aqueous washes of nonsterile soils, indicating that native microbial activity in these soils was suppressive to fungal growth. In contrast, both fungi grew on washes of autoclaved soil and in washes of nonsterile soil that were filter sterilized (J. Palumbo and T. O'Keeffe, data not shown), suggesting that the suppressive microbial activity in these soils required concurrent microbial metabolic activity. These soils were the source for isolation of several bacterial genera with antagonistic phenotypes, including Pseudomonas, Bacillus, Burkholderia, Wautersia, Stenotrophomonas, and Variovorax (31). In other studies, Pseudomonas spp. have been implicated as contributors to soil suppressiveness $(20,34,35)$ so it is not surprising that fungal growth was suppressed in these native soils. The use of autoclaved soils in this study allowed us to observe specific effects of individual antagonists that would not be measurable otherwise. This approach has been taken in other studies to demonstrate efficacy of bacterial antagonists in reducing soil populations of A. flavus and $F$. verticillioides (18).

P. chlororaphis strain JP1015 was more inhibitory to A. flavus in soil, and was less dose-dependent than P. fluorescens strain JP2175 (Figs. 1 and 2). Bacterial populations were more stable in F2 soil than in F6 soil (Fig. 3), suggesting possible soil-specific effects on individual bacterial isolates. However, the significant decline in $P$. chlororaphis strain JP1015 populations in F6 soil, particularly at low inoculum levels, occurred in coculture with $A$. flavus but not in coculture with $F$. verticillioides (T. O'Keeffe and 


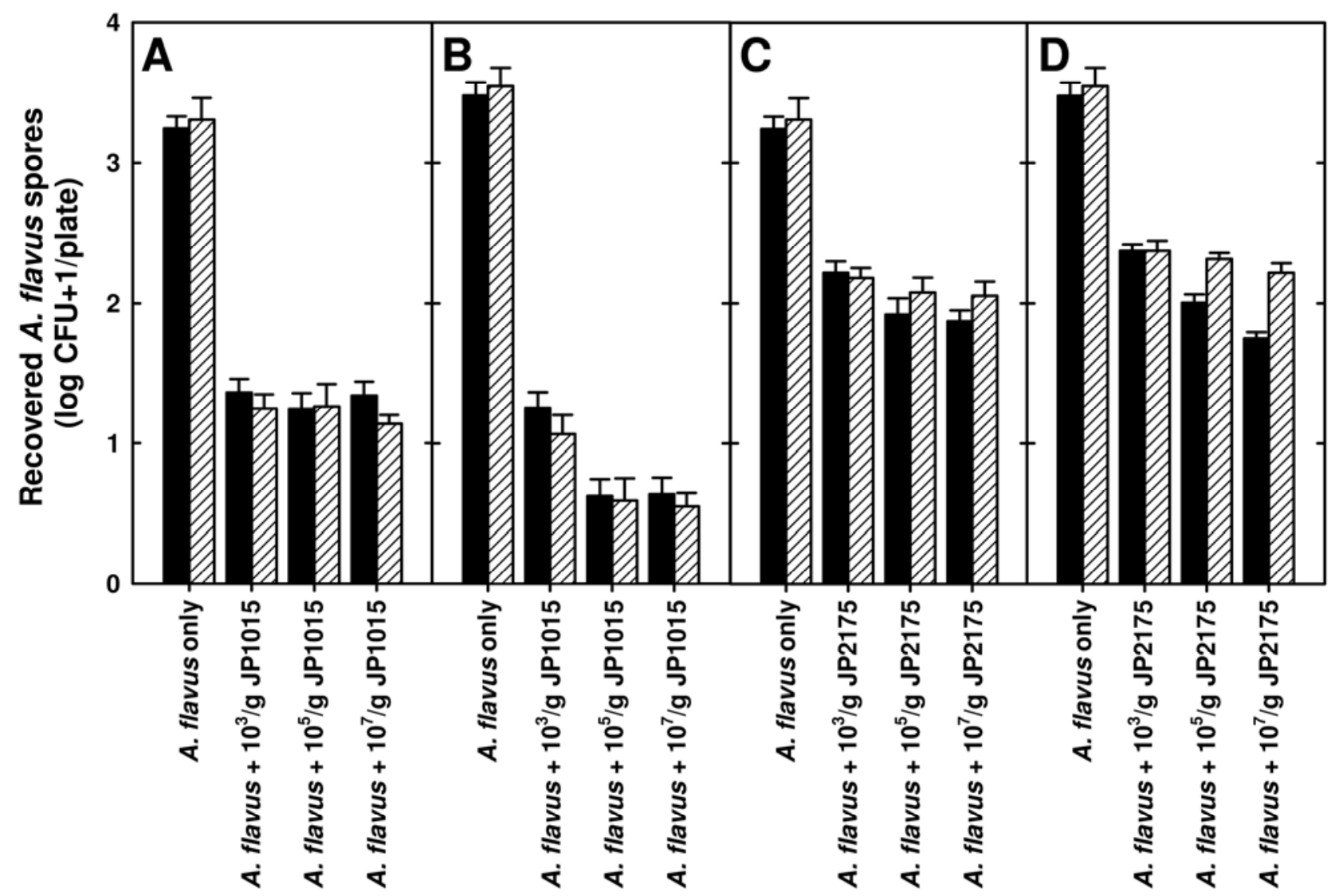

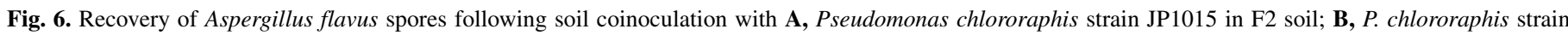

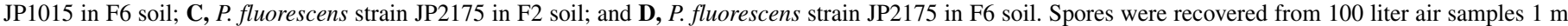

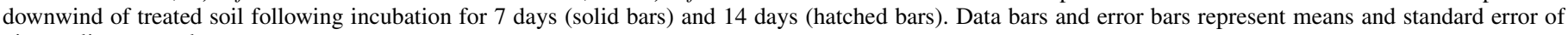
nine replicate samples per treatment.

A. Kattan, data not shown), indicating that fitness of this bacterium is influenced by both soil and fungal factors. Inhibition of A. flavus growth by $P$. fluorescens strain JP2175 correlated with initial inoculum level in soil assays (Fig. 2), even though bacterial populations at all inoculum levels were the same by day 3 (Fig. 4). It is possible that the dose-dependent inhibition by strain JP2175 may in part be due to lower initial growth rate, or that production of inhibitory factors occurs at the earliest stages of the microbial interaction. These results necessitate further studies to determine bacterial survival and antifungal activity in soils under different conditions, such as soil moisture and temperature.

Windborne spore dispersal is a major mechanism of crop contamination by aflatoxigenic Aspergilli $(19,29)$, as well as other mycotoxigenic fungi such as Fusarium spp. $(25,30)$. Because environmental sampling of airborne spores is highly variable, depending on humidity, wind speed, collection site, etc., the development of a small-scale apparatus for sampling under controlled conditions is advantageous for modeling the effects of particular treatments on spore dispersal. In the current study, we used a bench top wind chamber (Fig. 5) to collect airborne $A$. flavus spores at a distance of $1 \mathrm{~m}$ from inoculated soil using defined parameters (soil surface area, wind speed, and air volume sampled). Using this methodology, we demonstrated that bacterial antagonism, which reduced vegetative fungal growth in soil, directly resulted in reduced numbers of conidia that could be carried by wind (Fig. 6). The information provided by these experiments serves as a basis for future studies to investigate the potential for field application of these bacteria and to determine their effects on soil populations and airborne dispersal of $A$. flavus and resulting fungal colonization and aflatoxin contamination of susceptible crops.

\section{ACKNOWLEDGMENTS}

We thank M. Kersh for technical assistance and R. Haff and E. Jackson for helpful discussions. This work was supported by the U.S. Department of Agriculture, Agricultural Research Service, CRIS project 5325-42000036-00D.

\section{LITERATURE CITED}

1. Abbas, H. K., Williams, W. P., Windham, G. L., Pringle, H. C., 3rd, Xie, W., and Shier, W. T. 2002. Aflatoxin and fumonisin contamination of commercial corn (Zea mays) hybrids in Mississippi. J. Agric. Food Chem. 50:5246-5254.

2. Abbas, H. K., Zablotowicz, R. M., Bruns, H. A., and Abel, C. A. 2006. Biocontrol of aflatoxin in corn by inoculation with non-aflatoxigenic Aspergillus flavus isolates. Biocontrol Sci. Technol. 16:437-449.

3. Anjaiah, V., Thakur, R. P., and Koedam, N. 2006. Evaluation of bacteria and Trichoderma for biocontrol of pre-harvest seed infection by Aspergillus flavus in groundnut. Biocontrol Sci. Technol. 16:431-436.

4. Bacon, C. W., and Nelson, P. E. 1994. Fumonisin production in corn by toxigenic strains of Fusarium moniliforme and Fusarium proliferatum. J. Food Prot. 57:514-521.

5. Badii, F., and Moss, M. O. 1988. The effect of the fungicides tridemorph, fenpropiomorph and fenarimol on growth and aflatoxin production by Aspergillus parasiticus Speare. Lett. Appl. Microbiol. 7:37-39.

6. Bakan, B., Melcion, D., Richard-Molard, D., and Cahagnier, B. 2002. Fungal growth and Fusarium mycotoxin content in isogenic traditional maize and genetically modified maize grown in France and Spain. J. Agric. Food Chem. 50:728-731.

7. Bluma, R. V., and Etcheverry, M. G. 2006. Influence of Bacillus spp. isolated from maize agroecosystem on growth and aflatoxin $\mathrm{B}(1)$ production by Aspergillus section Flavi. Pest Manag. Sci. 62:242-251.

8. Brown, R. L., Chen, Z. Y., Menkir, A., Cleveland, T. E., Cardwell, K., Kling, J., and White, D. G. 2001. Resistance to aflatoxin accumulation in kernels of maize inbreds selected for ear rot resistance in West and 
Central Africa. J. Food Prot. 64:396-400.

9. Brown, R. L., Cotty, P. J., and Cleveland, T. E. 1991. Reduction in aflatoxin content of maize by atoxigenic strains of Aspergillus flavus. J. Food Prot. 54:623-626.

10. Bruns, H. A. 2003. Controlling aflatoxin and fumonisin in maize by crop management. J. Toxicol. Tox. Rev. 22:153-173.

11. Buchanan, R. L., Jones, S. B., and Stahl, H. G. 1987. Effect of miconazole on growth and aflatoxin production by Aspergillus parasiticus. Mycopathologia 100:135-144.

12. CAST (Council for Agricultural Science and Technology). 2003. Mycotoxins: Risks in Plant, Animal, and Human Systems, Task Force Report, No. 139. Council for Agricultural Science and Technology, Ames, IA.

13. Cavaglieri, L., Orlando, J., and Etcheverry, M. 2005. In vitro influence of bacterial mixtures on Fusarium verticillioides growth and fumonisin B1 production: Effect of seeds treatment on maize root colonization. Lett. Appl. Microbiol. 41:390-396.

14. Cavaglieri, L., Orlando, J., Rodriguez, M. I., Chulze, S., and Etcheverry, M. 2005. Biocontrol of Bacillus subtilis against Fusarium verticillioides in vitro and at the maize root level. Res. Microbiol. 156:748-754.

15. Diener, U. L., Cole, R. J., Sanders, T. H., Payne, G. A., Lee, L. S., and Klich, M. A. 1987. Epidemiology of aflatoxin formation by Aspergillus flavus. Annu. Rev. Phytopathol. 25:249-270.

16. Dorner, J. W., Cole, R. J., and Wicklow, D. T. 1999. Aflatoxin reduction in corn through field application of competitive fungi. J. Food Prot. 62:650656.

17. Dowd, P. F. 2003. Insect management to facilitate preharvest mycotoxin management. J. Toxicol. Tox. Rev. 22:327-350.

18. Etcheverry, M. G., Scandolara, A., Nesci, A., Vilas Boas Ribeiro, M. S., Pereira, P., and Battilani, P. 2009. Biological interactions to select biocontrol agents against toxigenic strains of Aspergillus flavus and $F u$ sarium verticillioides from maize. Mycopathologia 167:287-295.

19. Fennell, D. I., Kwolek, W. F., Lillehoj, E. B., Adams, G. A., Bothast, R. J., Zuber, M. S., Calvert, O. H., Guthrie, W. D., Bockholt, A. J., Manwiller, A., and Jellum, M. D. 1977. Aspergillus flavus presence in silks and insects from developing and mature corn ears. Cereal Chem. 54:770-778.

20. Haas, D., and Keel, C. 2003. Regulation of antibiotic production in rootcolonizing Pseudomonas spp. and relevance for biological control of plant disease. Annu. Rev. Phytopathol. 41:117-153.

21. Hernández-Rodríguez, A., Heydrich-Pérez, M., Acebo-Guerrero, Y., Velazquez-del Valle, M. G., and Hernández-Lauzardo, A. N. 2008. Antagonistic activity of Cuban native rhizobacteria against Fusarium verticillioides (Sacc.) Nirenb. in maize (Zea mays L.). Appl. Soil Ecol. 39:180-186.

22. Jayashree, T., and Subramanyam, C. 2000. Oxidative stress as a prerequisite for aflatoxin production by Aspergillus parasiticus. Free Radic. Biol. Med. 29:981-985.

23. Kim, J. H., Campbell, B. C., Yu, J., Mahoney, N., Chan, K. L., Molyneux,
R. J., Bhatnagar, D., and Cleveland, T. E. 2005. Examination of fungal stress response genes using Saccharomyces cerevisiae as a model system: Targeting genes affecting aflatoxin biosynthesis by Aspergillus flavus Link. Appl. Microbiol. Biotechnol. 67:807-815.

24. Magg, T., Melchinger, A. E., Klein, D., and Bohn, M. 2002. Relationship between European corn borer resistance and concentration of mycotoxins produced by Fusarium spp. in grains of transgenic Bt maize hybrids, their isogenic counterparts, and commercial varieties. Plant Breed. 121:146154.

25. Martin, R. A. 1988. Use of a high-through-put jet sampler for monitoring viable airborne propagules of Fusarium in wheat. Can. J. Plant Pathol. 10:359-360.

26. Menkir, A., Brown, R. L., Bandyopadhyay, R., Chen, Z. Y., and Cleveland, T. E. 2006. A USA-Africa collaborative strategy for identifying, characterizing, and developing maize germplasm with resistance to aflatoxin contamination. Mycopathologia 162:225-232.

27. Munkvold, G. P. 2003. Cultural and genetic approaches to managing mycotoxins in maize. Annu. Rev. Phytopathol. 41:99-116.

28. Nesci, A. V., Bluma, R. V., and Etcheverry, M. G. 2005. In vitro selection of maize rhizobacteria to study potential biological control of Aspergillus section Flavi and aflatoxin production. Eur. J. Plant Pathol. 113:159-171.

29. Olanya, O. M., Hoyos, G. M., Tiffany, L. H., and McGee, D. C. 1997. Waste corn as a point source of inoculum for Aspergillus flavus in the corn agroecosystem. Plant Dis. 81:576-581.

30. Ooka, J. J., and Kommedahl, T. 1977. Wind and rain dispersal of Fusarium moniliforme in corn fields. Phytopathology 67:1023-1026.

31. Palumbo, J. D., O'Keeffe, T. L., and Abbas, H. K. 2007. Isolation of maize soil and rhizosphere bacteria with antagonistic activity against Aspergillus flavus and Fusarium verticillioides. J. Food Prot. 70:16151621.

32. Payne, G. A. 1992. Aflatoxin in maize. Crit. Rev. Plant Sci. 10:423-440.

33. Pitt, J. I., Hocking, A. D., and Glenn, D. R. 1983. An improved medium for the detection of Aspergillus flavus and A. parasiticus. J. Appl. Bacteriol. 54:109-114.

34. Raaijmakers, J. M., Bonsall, R. F., and Weller, D. M. 1999. Effect of population density of Pseudomonas fluorescens on production of 2,4diacetylphloroglucinol in the rhizosphere of wheat. Phytopathology $89: 470-475$

35. Raaijmakers, J. M., Weller, D. M., and Thomashow, L. S. 1997. Frequency of antibiotic-producing Pseudomonas spp. in natural environments. Appl. Environ. Microbiol. 63:881-887.

36. Robens, J., and Cardwell, K. F. 2005. The costs of mycotoxin management in the United States. In: Aflatoxin and Food Safety. H. K. Abbas, ed. Taylor \& Francis, Boca Raton, FL.

37. Wicklow, D. T., Roth, S., Deyrup, S. T., and Gloer, J. B. 2005. A protective endophyte of maize: Acremonium zeae antibiotics inhibitory to Aspergillus flavus and Fusarium verticillioides. Mycol. Res. 109:610-618. 